\title{
Hubungan kadar asam urat dengan status gizi pada remaja di Kecamatan Bolangitang Barat Kabupaten Bolaang Mongondow Utara
}

\author{
${ }^{1}$ Alvin Budiono \\ ${ }^{2}$ Aaltje E. Manampiring \\ ${ }^{2}$ Widhi Bodhi \\ Email: alvinhumizar@yahoo.com
}

${ }^{1}$ Kandidat Skripsi Fakultas Kedokteran Universitas Sam Ratulangi Manado

${ }^{2}$ Bagian Kimia Fakultas Kedokteran Universitas Sam Ratulangi Manado

\begin{abstract}
Hyperuricemia is one state that is now likely to be obtained at adolescent. The state of hyperuricemia can be influenced by many factor, for example is the nutritional status. This study aims to determine the correlation between uric acid levels and nutritional status in adolescents in the District of West Bolangitang. This study is cross-sectional analytic. The subjects were adolescents from middle and high school in the District of West Bolangitang. Respondents were entering the study were 60 children, 16 boys and 44 girls. From the results obtained hyperuricaemia 16 children, and $12(75 \%)$ were obese, 1 underweight, normal 2 and 1 overweight. Conclusion: There is a correlation between uric acid levels and nutritional status in adolescents in the District of West Bolangitang
\end{abstract}

Keywords: hyperurisemia, uric acid, nutritional status

\begin{abstract}
Abstrak: Hiperurisemia merupakan salah satu keadaan yang sekarang cenderung didapatkan pada usia yang lebih muda. Keadaan hiperurisemia ini dapat dipengaruhi oleh berbagai hal, salah satu contohnya adalah status gizi. Penelitian ini bertujuan untuk mengetahui hubungan antara kadar asam urat dengan status gizi pada remaja di Kecamatan Bolangitang Barat. Penelitian ini bersifat cross-sectional analitik. Subjek penelitian ini adalah remaja dari SMP dan SMA di Kecamatan Bolangitang Barat. Responden yang mengikuti penelitian berjumlah 60 anak, 16 laki-laki dan 44 perempuan. Dari hasil pemeriksaan didapatkan 16 anak hiperurisemia, dan $12(75 \%)$ diantaranya obesitas, 1 underweight, 2 normal dan 1 overweight. Simpulan: Terdapat hubungan antara kadar asam urat dengan status gizi pada remaja di Kecamatan Bolangitang Barat
\end{abstract}

Kata kunci: hiperurisemia, kadar asam urat, status gizi

Asam urat sudah dikenal sejak ribuan tahun yang lalu. Asam urat merupakan substansi akhir dari hasil metabolisme purin dalam tubuh. Asam urat yang berlebihan tidak akan tertampung dan termetabolisme seluruhnya dalam tubuh yang mengakibatkan peningkatan kadar asam urat dalam darah yang disebut juga hiperurisemia. ${ }^{1}$

Penyakit asam urat berkaitan dengan pola asupan makanan, sehingga salah satu cara pencegahan dengan mengontrol pola asupan makanan. Jika tidak mengontrol pola asupan, kadar asam urat dalam darah akan berlebihan dan menimbulkan penumpukan kristal asam urat yang apabila terbentuk pada cairan sendi, maka akan terjadi penyakit asam urat. ${ }^{2}$

Faktor risiko yang mempengaruhi tingginya asam urat adalah umur, genetik, asupan purin yang berlebihan, kegemukan, penyakit jantung dan konsumsi obat-obatan tertentu (diuretika) dan gangguan fungsi ginjal. Konsumsi purin yang terdapat dalam 
Budiono, Manampiring, Bodhi: Hubungan kadar asam...

daging dan seafood berhubungan terhadap risiko peningkatan kadar asam urat, sedangkan produk susu dapat menurunkan risiko gout dan konsumsi purin dari tumbuh-tumbuhan tidak berpengaruh terhadap risiko gout. Sedangkan konsumsi karbohidrat kompeks seperti nasi, roti, ubi jalar dan ketela dapat memacu pembuangan kelebihan asam urat dalam darah(Sustrani, 2004). ${ }^{3}$

Angka kejadian penyakit artritis gout cenderung memaski usia semakin muda, yaitu usia produktif dimana diketahui prevalensi asam urat di Indonesia yang terjadi pada usia di bawah 34 tahun yaitu sebesar 32\% dengan kejadian tertinggi pada penduduk Minahasa sebesar 29,2\%. ${ }^{4}$

Obesitas juga bisa menjadi salah satu faktor pendukung terjadinya asam urat. Penyakit asam urat erat kaitannya dengan obesitas. konsumsi makanan berlemak, santan jeroan serta pola hidup. Orang yang gemuk cenderung memiliki kadar asam urat yang tinggi dalam darah. Sampai saat ini belum ada teori yang bisa menjelaskan mengapa kadar asam urat pada orang obesitas tinggi. Namun pada sebagian besar penelitian, kadar asam urat pada orang obesitas cenderung lebih tinggi dari normal. ${ }^{5,6}$

Penelitian ini bertujuan untuk mengetahui hubungan antara kadar asam urat dengan status gizi pada remaja di Kecamatan Bolangitang Barat

\section{METODE PENELITIAN}

Desain penelitian yang digunakan adalah penelitian analitik dengan pendekatan cross sectional. Penelitian dilakukan pada 10 Oktober 2016 di SMAN 1 Bolangitang Barat. Populasi penelitian ini adalah siswa-siswi SMP dan SMA yang ada di Kecamatan Bolangitang Barat. Sampel penelitian ini adalah siswa-siswi yang berumur 10-19 tahun. Variabel penelitian diantaranya jenis kelamin, indeks massa tubuh, status gizi dan kadar asam urat. Pemeriksaan ini dilakukan dengan memeriksa indeks massa tubuh dan darah responden. Data hasil pemeriksaan dimasukkan pada tabel status gizi dan kadar asam urat yang telah disusun dengan
Microsoft Word dan data diolah menggunakan program SPSS

\section{HASIL PENELITIAN}

Pada penelitian yang dilaksanakan di SMAN 1 Bolangitang Barat dengan total siswa-siswi berjumlah 60 orang, terdiri dari 14 orang (27\%) laki-laki dan perempuan 44 orang $(73 \%)$ perempuan.

Tabel 1. Distribusi berdasarkan jenis kelamin dan status gizi remaja di Bolangitang Barat

\begin{tabular}{ccccc}
\hline \multirow{2}{*}{ Status gizi } & \multicolumn{2}{c}{$\begin{array}{c}\text { Jenis } \\
\text { kelamin }\end{array}$} & n & \% \\
\cline { 2 - 3 } & L & P & & \\
\hline Underweight & - & 5 & 5 & 8 \\
Normal & 6 & 17 & 23 & 38 \\
Overweight & - & 3 & 3 & 5 \\
Obese & 10 & 19 & 29 & 49 \\
Total & 16 & 44 & 60 & 100 \\
\hline
\end{tabular}

Pada penelitian didapatkan 16 orang responden yang memiliki kadar asam urat diatas normal dan terdiri dari 4 (25\%) lakilaki dan 12 (75\%) perempuan.

Tabel 2. Distribusi Jenis kelamin dan kadar asam urat

\begin{tabular}{|c|c|c|c|c|}
\hline \multirow{2}{*}{$\begin{array}{c}\text { Kadar } \\
\text { asam urat }\end{array}$} & \multicolumn{2}{|c|}{ Jenis kelamin } & \multirow{2}{*}{$\mathbf{n}$} & \multirow{2}{*}{$\%$} \\
\hline & $\mathrm{L}$ & $\mathrm{P}$ & & \\
\hline Normal & 12 & 32 & 44 & 73 \\
\hline Tinggi & 4 & 12 & 16 & 27 \\
\hline Total & 16 & 44 & 60 & 100 \\
\hline
\end{tabular}

Tabel 3. Distribusi kadar asam urat dan status gizi

\begin{tabular}{ccccc}
\hline \multirow{2}{*}{ Status gizi } & \multicolumn{2}{c}{ Kadar } & & \\
& asam urat & \multirow{n}{n}{ n } & $\%$ \\
\cline { 2 - 3 } & Normal & Tinggi & & \\
\hline Underweight & 4 & 1 & 5 & 8 \\
Normal & 21 & 2 & 23 & 38 \\
Overweight & 2 & 1 & 3 & 5 \\
Obese & 17 & 12 & 29 & 49 \\
Total & 44 & 16 & 60 & 100 \\
\hline
\end{tabular}

Pada penelitian didapatkan dari 16 orang responden yang memiliki kadar asam urat diatas normal, $12(75 \%)$ diantaranya 
obesitas, $2(12,5 \%)$ normal, $1(6,25 \%)$ underweight dan $1(6,25 \%)$ overweight.

Pada uji tes normalitas didapatkan sampel tidak terdistribusi normal.

Tabel 4. Hasil uji normalitas sampel

\begin{tabular}{lccr}
\hline \multicolumn{4}{c}{ Kolmogorov-Smirnov $^{\mathrm{a}}$} \\
\hline & Statistic & $\mathrm{df}$ & Sig. \\
IMT & 0.165 & 60 & 0 \\
AsamUrat & 0.174 & 60 & 0 \\
\hline
\end{tabular}

Pada penelitian ini untuk mengetahui ada tidaknya hubungan antara kadar asam urat dengan status gizi, maka digunakan uji non-parametric Kruskal Wallis

Tabel 5. Uji non-parametric Kruskal-Wallis

\begin{tabular}{llrr}
\hline Gizi & N & $\begin{array}{c}\text { Mean } \\
\text { Rank }\end{array}$ \\
\hline \multirow{4}{*}{ AsamUrat } & Underweight & 5 & 13.3 \\
& Normal & 23 & 26.15 \\
& Overweight & 3 & 17.17 \\
& Obesitas & 29 & 38.29 \\
& Total & 60 & \\
\hline
\end{tabular}

\begin{tabular}{lr}
\hline \multicolumn{2}{c}{ Test Statistics ${ }^{\text {a,b }}$} \\
\hline & AsamUrat \\
Chi-Square & 13.864 \\
df & 3 \\
Asymp. Sig. & 0.003 \\
\hline
\end{tabular}

\section{BAHASAN}

Penelitian kadar asam urat dan status gizi pada remaja di Kecamatan Bolangitang Barat yang dengan total responden sebanyak 60 orang. Didapatkan hasil karakteristik subjek terbanyak pada penelitian ini adalah perempuan dengan persentase $73 \%$ dan sisanya adalah laki-laki dengan persentase $27 \%$. Karakteristik status gizi terbanyak pada penelitian ini adalah obese dengan persentase $49 \%$ dan sisanya normal dengan persentase $38 \%$, underweight $8 \%$ dan overweight dengan persentase $5 \%$. Penelitian ini sesuai dengan hasil penelitian yang dilakukan di Kota Tomohon menyebutkan bahwa prevalensi obesitas lebih tinggi pada perempuan dibandingkan dengan laki-laki. ${ }^{7}$

Pada uji non-parametric Kruskal
Wallis didapatkan $p=0,003$. Hal ini menyebabkan $\mathrm{H}_{0}$ ditolak $(\mathrm{p}<0,005)$ yang artinya terdapat hubungan antara kadar asam urat dengan status gizi pada remaja di Kecamatan Bolangitang Barat

Status gizi dapat mempengaruhi kadar asam urat dalam darah, sebagai contoh obesitas yang merupakan kondisi dimana terjadi kelebihan lemak tubuh yang mengakibatkan meningkatnya metabolisme purin, disamping itu juga berhubungan dengan luas permukaan tubuh yang lebih besar dapat menyebabkan oksidasi LDL meningkat dan reaksi inflamasi yang memicu apoptosis sehingga meningkatkan suplai purin dan aktivitas dri enzim xanthine oksidase yang berujung pada stres oksidatif. $^{8}$

Pada era globalisasi sekarang ini, banyak produk cepat saji atau yang lebih dikenal dengan junk food beredar dan dapat diperoleh dengan mudah. Para remaja sekarang ini cenderung menyukai makanan cepat saji yang memiliki kadar lemak lebih tinggi. Asam urat sendiri merupakan isu penting di Indonesia. Bahkan sekarang penyakit asam urat tidak hanya pada orang dewasa saja, tetapi sering ditemukan dan sudah menjadi masalah bagi remaja. Tubuh menghasilkan asam urat melalui proses metabolisme normal. Tubuh menyediakan $85 \%$ senyawa purin untuk kebutuhan setiap hari. Ini berarti bahwa kebutuhan purin dari makanan hanya sekitar $15 \%$. Banyak orang yang mengonsumsi makanan tanpa mempertimbangkan kandungan gizi yang ada didalamnya. ${ }^{9}$

Beberapa dari makanan yang sering kita konsumsi seperti jeroan, udang, kangkung dan ikan putih mengandung purin yang sangat tinggi. Produk makanan yang mengandung purin tinggi kurang baik bagi orang tertentu yang mempunyai riwayat keluarga dengan gangguan metabolisme asam urat. Jika tidak dikendailkan maka jumlah asam urat dapat meningkat melebihi batas normal. ${ }^{10}$ Oleh karena purin merupakan hasil dari metabolisme tubuh, maka perlu diingatkan kepada seseorang dengan kadar asam urat tinggi harus hati-hati dengan penyakit yang 
berhubungan dengan metabolisme seperti penyakit jantung, kencing manis, dan penyakit yang berdampak langsung pada ginjal. Kenyataan ini sangat erat hubungannya dengan tradisi, budaya dan pola makan masyarakat Bolaang Mongondow. Penduduk di daerah Bolaang Mongondow memiliki prevalensi tinggi terkena penyakit asam urat. Ini karena kebiasaan mereka mengkonsumsi makanan laut tertentu dan gemar minum alkohol. Masyarakat Bolaang Mongondow penting mengubah kebiasaan dan pola makan dan aktivitasnya dalam menjaga kadar asam urat agar berada dalam batas normal.

\section{SIMPULAN}

Berdasarkan hasil penelitian yang dilakukan pada siswa di Kecamatan Bolangitang Barat dengan umur 10-19 tahun, disimpulkan bahwa ada hubungan antara status gizi dengan kadar asam urat terlebih khusus pada status gizi obesitas

\section{SARAN}

Perlu dilakukan upaya promotif mengenai asupan makanan yang seimbang dan olahraga yang teratur. Perlu dilakukan penelitian lebih lanjut mengenai hubungan asam urat terutama dengan kuisioner makanan dan genetik, agar bisa mendeteksi faktor-faktor pencetus asam urat lainnya.. Perlu dilakukan edukasi kepada responden yang memiliki kadar asam urat yang tinggi tentang diet rendah purin

\section{DAFTAR PUSTAKA}

1. Drug and disease of hyperuricemia. Medscape. Avalaible from: http://emedicine.medscape.com/articl e/241767-overview
2. All About Gout And Diet. UK Gout Society. Avalaible from: http://www.ukgoutsociety.org/docs/g outsociety-allaboutgoutanddiet0113.pdf

3. Lina N, Setiyono A. Analisis kebiasaan makan yang menyebabkan peningkatan Kadar Asam Urat. Jurnal Kesehatan Komunitas Indonesia. 2014;10:2

4. Kumalasari T, Saryono, Purnawan Iwan. Hubungan Indeks Massa Tubuh dengan Kadar Asam Urat Darah pada Penduduk Desa Banjaranyar Kecamatan Sokaraja Kabupaten Banyumas. Jurnal Soedirman. 2009;4:3

5. Drug and Disease of Hyperuricemia. Medscape. Avalaible from: http://emedicine.medscape.com/articl e/241767-overview\#a6

6. Setyowati, Syamsiatun N, Herawati. Obesitas, Pola Konsumsi Sumber Purin dan Lemak sebagai Faktor Risiko Terjadinya Asam Urat (gout) pada Pasien Rawat Jalan di Puskesmas Gamping II Sleman Yogyakarta. Jurnal Nutrisi. 2014;2:1

7. Marcel H. Prevalensi Hiperurisemia pada Remaja Obese di SMA Don Bosco Bitung. Manado. 2012

8. Acharya C, Sharma A, Kantharia ND. Involvement of oxidative stress in patients of gout and antioxidant effect of allopurinol. UKM Journal. 2014

9. Mengenal Lebih Jauh Asam Urat. Kedokteran Holistik. Avalaible from: http://kesehatanholistik.com/asamurat/

10.Ngantung E. Karya Tulis Ilmiah Sarjana. Profil Kadar Asam Urat pada Remaja Obes di Kota Bitung. Fakultas Kedokteran Universitas Sam Ratulangi. 2013 